

\section{A logística e as indústrias automobilísticas no Brasil}

Kátia Kelly Lacerda de Freitas; Luiz Andrei Gonçalves Pereira; Pedro Ivo Jorge Gomes

\section{Introdução}

O termo logística refere-se ao ato de "planejar, programar e controlar de maneira eficiente o fluxo de armazenagem de produtos, bem como os serviços e informações associados, cobrindo desde a origem até o ponto de consumo”. (NOVAES, 2001, p.36)

O setor automotivo, neste sentido, pode ser considerado estratégico na estrutura econômica, principalmente por envolver diversos processos no setor produtivo que interagem com setores diversos, sendo, portanto, consideráveis para a Gestão da Cadeia de Suprimentos - GCS.

Segundo Pires (2004), nos últimos cem anos a indústria automobilística tornou-se um dos principais e mais importantes segmentos industriais, em função do nível e constância do desenvolvimento de técnicas e melhoramentos para o setor, especialmente na organização do sistema produtivo intra e interfirma.

Neste sentido, o presente trabalho busca identificar e compreender a utilização da rede de transportes do setor automobilístico exportador visto que, como descreve Ballou (1993), o transporte é uma das atividades primárias no que tange à logística, tendo, portanto, grande importância para as atividades de movimentação. Logo, a valorização deste estudo reside em destacar o papel do desenvolvimento de uma logística eficaz de transporte especificamente no que concerne ao setor automobilístico, que tanto contribui para o desenvolvimento econômico no país.

A pesquisa versa responder ao seguinte questionamento: Quais os problemas enfrentados pelas indústrias automobilísticas no Brasil na logística de importação das suas cargas?

O objetivo geral do trabalho é identificar e compreender utilização da rede de transportes na cadeia de suprimentos do setor automobilístico.

Metodologicamente, desenvolveu-se uma pesquisa bibliográfica, utilizando para referencial teórico autores como: Ballou (1993); Ballou (2007), Pires (2004), Novaes (2001), Moura (2004), Nabuco, Neves e Neto (2002), dentre outros, cujas ideias dão suporte para uma discussão sobre que parte da logística genericamente e possibilita sua expansão para diferentes vertentes, no caso específico deste trabalho, sobre a logística nos transportes automobilísticos.

O texto encontra-se dividido em quatro sessões, além desta introdução. A primeira parte discute-se sobre o surgimento do setor de logística no Brasil. Em seguida, fez-se uma 


\section{A logística e as indústrias automobilísticas no Brasil}

Kátia Kelly Lacerda de Freitas; Luiz Andrei Gonçalves Pereira; Pedro Ivo Jorge Gomes

abordagem acerca das montadoras de automóveis em nível nacional. Logo após discutiu-se sobre a estrutura de redes de transporte das indústrias automobilísticas e os mercados importadores das indústrias Automobilísticas no Brasil. E, por fim, as considerações finais.

\section{O Surgimento do setor de logística no Brasil}

A discussão de logística passou a ganhar maior atenção a partir de meados da década de 1950, em função do término da Segunda Guerra Mundial e com o ápice do processo de industrialização no mundo.

Para Ballou, a logística associa-se ao estudo e a administração dos fluxos de bens e serviços e da informação associada, que os põe em movimento. Vencer tempo e distância na movimentação de bens ou na entrega de serviços de forma eficaz e eficiente e a tarefa do profissional de logística (BALLOU, 2007). Segundo o autor, a logística se estrutura em níveis de serviços sustentados em três atividades básicas e que se desdobram nas atividades secundárias com foco no serviço de planejamento e gerenciamento de fluxos (BALLOU, 1993). O objetivo é utilizar dos fluxos de informação para colocar os produtos em movimento de forma a proporcionar níveis de serviços satisfatórios, e, consequentemente, com custos proporcionais às condições da infraestrutura, demanda e oferta de serviços logísticos especializados, além de outros fatores não menos relevantes (BALLOU, 2007:23).

Segundo Moura logística é:

$\mathrm{O}$ processo de planejamento, implementação, controle do fluxo e armazenagem eficiente de matérias-primas, estoque em processo, produto acabado e informações relacionadas, desde o ponto de origem até o ponto de consumo, com objetivo de atender aos requisitos do cliente, em uma mesma organização. Em um contexto industrial a arte e ciência de administração e engenharia para obter, produzir e distribuir materiais fabricados ou industrializados a um local específico e em quantidades específicas (MOURA, 2004, p.136).

A Association Française des Logisriciens d'Entreprises, define logística como sendo o conjunto de atividades que tem por fim a colocação, com um custo mínimo, de uma qualidade de produto no local e no momento em que existe a demanda.

Nesse sentido, é de responsabilidade da logística as operações ligadas ao movimento de produtos, desde a localização das fábricas e correlatos, abastecimentos, gestão física de produtos, embalagem, entre outros, pois, todas as operações que condicionam o movimento 


\section{A logística e as indústrias automobilísticas no Brasil}

Kátia Kelly Lacerda de Freitas; Luiz Andrei Gonçalves Pereira; Pedro Ivo Jorge Gomes

dos produtos, tais como: localização das fábricas e entrepostos, abastecimentos, gestão física de produtos em curso de fabrico, embalagem, formação e gestão de estoques, manutenção e preparação das encomendas, transportes e circuitos de entrega (BALLOU, 2007).

A logística trata da criação de valor - valor para os clientes e fornecedores da empresa, e valor para todos aqueles que têm nela interesses diretos. $\mathrm{O}$ valor da logística é manifestado primeiramente em termos de tempo e lugar. A boa administração logística interpreta cada atividade na cadeia de suprimentos como contribuinte do processo de agregação de valor (BALLOU, 2007; MOURA, 2004; NOVAES, 2001).

Dessa forma, o presente trabalho adota a definição de Ballou, que define a logística como o processo de planejar, organizar e administrar a movimentação desde a matéria prima ao produto acabado, vencendo a distância, no menor tempo possível, de forma eficaz e eficiente, sempre procurando atender as necessidades dos consumidores, com o menor custo possível.

\section{As montadoras de automóveis no Brasil}

As primeiras empresas do setor automobilístico implantadas no Brasil foram a Ford Motors do Brasil em 1919 e a General Motors do Brasil - GMB em 1925. Estas escolheram o estado de São Paulo para começarem suas atividades, que na perspectiva de Juerguen R. Languenbuch (s/n), esta escolha se deve ao desenvolvimento econômico apresentado pela cidade.

Em 1953, o governo brasileiro resolveu aplicar a adoção de tarifas altas, com o objetivo de estimular a redução das importações de automóveis, usando como argumento a instabilidade apresentada pela balança comercial. Entretanto, com o passar dos anos, percebeu que era necessário pensar novos modelos a partir da industrialização vivida até então, principalmente pela importância exercida pelos automóveis e componentes na pauta de importações (BOTELHO, 2002).

Em meados do século XX, no processo de industrialização, com a crescente subordinação das políticas anti-inflacionárias, houve a adesão de mecanismos visando o crescimento econômico via abertura comercial, baseada na associação entre Estado, capital privado nacional e capital estrangeiro. Neste período, a economia brasileira sofreu diversas mudanças, situação que provocou a busca por recursos e mão de obras mais baratos, bem como a busca por incentivos fiscais. 


\section{A logística e as indústrias automobilísticas no Brasil}

Kátia Kelly Lacerda de Freitas; Luiz Andrei Gonçalves Pereira; Pedro Ivo Jorge Gomes

Além disso, havia subsídio e protecionismo às empresas estrangeiras do setor que implantassem unidades no país como forma de atrair este tipo de atuação para o país. Vale ressaltar que além destes incentivos, essas empresas encontravam aqui um cenário atraente, visto que podiam contar com um mercado interno em desenvolvimento, mão de obra barata, além de infraestrutura compatível com a demanda.

O maior destaque nesta época foi para o estado de São Paulo que obteve maior concentração espacial de indústrias no processo de industrialização, tendo como ápice a década de 1970, sendo responsável por $40 \%$ da renda nacional e $58 \%$ da produção industrial, sendo a região metropolitana com destaque para a sua área metropolitana, que alcançou $44 \%$ da produção industrial do país naquele ano (DINIZ, 2000). Muitos fatores foram essenciais para atração de indústrias no estado, tais como, por exemplo, pavimentação das rodovias e terraplanagem de lugares acidentados, entretanto, possuíam localização privilegiada (BOTELHO, 2002).

Botelho (2002) ainda pontua a diminuição dessa concentração espacial para pontos específicos do país, ressaltando como caso mais expressivo de desconcentração industrial intra-estadual o da indústria paulista, sendo perceptível a perda da posição relativa da Região Metropolitana de São Paulo para as demais sub-regiões do estado, especialmente as do interior.

Para Wanderley (2002), o período de 1950 a 1960 foi bastante decisivo para a implementação da indústria automobilística no Brasil justamente pelas facilidades que foram concedidas pelo Estado, como, por exemplo, o Programa de Metas, iniciado no governo de Juscelino Kubitschek, que acabou beneficiando de maneira mais incisiva a região Sudeste.

Entre as décadas de 1970 e 1980 o Brasil entra num moderado processo de desconcentração, sendo esta época definida por Guimarães Neto (1989), como um tempo de integração produtiva entre as regiões, quando a produção começa a ser redirecionada para regiões diferentes, seguida da migração de capital. Wanderley (2002) destaca os Planos Diretores da SUDENE e a diversificação de incentivos de crédito.

Diniz (1993) explicita alguns dos principais pontos referentes às deseconomias de aglomeração que apareceram nas regiões metropolitanas de São Paulo e Rio de Janeiro e cooperaram para o fenômeno da desconcentração citado anteriormente nos anos de 1970, sendo eles: aumento do preço da terra e dos aluguéis, dos salários relativos, custos de congestionamento e transporte, assim como pressão sindical e greves que cresciam e os controles ambientais. 


\section{A logística e as indústrias automobilísticas no Brasil}

Kátia Kelly Lacerda de Freitas; Luiz Andrei Gonçalves Pereira; Pedro Ivo Jorge Gomes

Neste mesmo sentido, Diniz e Crocco (1996) acrescentam o desenvolvimento da infraestrutura econômica de transporte, energia e telecomunicações e seus impactos, a intenção notória da promoção de desconcentração pela política econômica e o aumento da produção agrícola e mineral e alargamento de seus alcances de cultivo. Em decorrência da desconcentração, nos anos de 1970, foram instaladas mais duas novas indústrias, a Fiat em Betim em 1973 e a Volvo em Curitiba em 1978, em função de incentivos fiscais recebidos.

A partir da década de 1990, com abertura do mercado interno ao comércio internacional, o setor automobilístico, assim como outros setores, passou por um processo de reestruturação, dando espaço para práticas mais flexíveis, fazendo com que houvesse a evolução do fordismo, que até então era adotado, para o toyotismo.

É interessante ponderar que mesmo experimentando várias mudanças, estas não foram experimentadas por todos os setores, inclusive empresas do mesmo ramo. Dentre as ações adotadas pelas empresas está o aumento da produtividade e lucros e para tanto, baseadas na redução no número de postos de trabalho, mudanças experimentadas no momento em que iniciava a inserção de outras empresas concorrentes.

Desta forma, pode-se inferir que o processo de industrialização brasileiro, até 1990, ocorreu não pela ampliação do mercado e sim pela "substituição das importações", ou seja, induzido pela política adotada no país como forma de incentivar a produção local a fim de aperfeiçoar a produtividade e logo, a impulsionar as exportações.

Os anos 2000 foram marcados pela entrada de novas indústrias no setor automotivo, o que rendeu ao Brasil o primeiro lugar no ranking mundial pelo número de montadoras instaladas, conforme aponta Rocha Filho:

As mudanças no setor automotivo ocorreram simultaneamente a entrada de novos produtores de veículos no mercado nacional e ao aumento da internacionalização da cadeia produtiva. A partir do ano 2000, 17 marcas de automóveis passaram a atuar no mercado brasileiro, o que coloca o Brasil como o primeiro do mundo em número de montadoras instaladas. Assim, a competição no mercado nacional tornou-se mais acirrada, pois entrou no mercado a Chrysler, com suas vans ou jipes; Honda, Hyundai, BMW, Mercedes-Benz, Renault, Peugeot, Toyota e outros, como a Mitsubishi, que pretendem produzir automóveis no Brasil (ROCHA FILHO, 1998, p. 22).

Percebe-se que mesmo com a abertura econômica que marcou a década de 90, a indústria automobilística buscou se instalar no Brasil considerando, principalmente, o mercado consumidor, subsídios e barreiras comerciais. Embora o estado de São Paulo tenha muita força no setor, filiais de grandes marcas foram implantadas em regiões diferentes. $\mathrm{O}$ 


\section{A logística e as indústrias automobilísticas no Brasil}

Kátia Kelly Lacerda de Freitas; Luiz Andrei Gonçalves Pereira; Pedro Ivo Jorge Gomes

que se percebe ao longo dos anos é que o estado de São Paulo continua sendo o foco de grandes empresas do setor automobilístico, tendo a maior concentração destas na região metropolitana, com exceção de uma sede no Rio e em Minas e duas delas em Curitiba.

\section{A estrutura de redes de transportes das Indústrias Automobilísticas}

O setor industrial é considerado um dos mais dinâmicos da economia mundial por depender de elementos que costumam variar como economia, desenvolvimento regional, recursos naturais, capital humano, dentre outros. Possui muitas barreiras econômicas e tecnológicas à entrada de novos competidores, além de ser um mercado oligopolizado.

O ramo automobilístico exerce muitas influências sobre outros setores da economia, bem como em relação à divisão e organização do espaço. Considerando os modelos como o Fordismo, implantado no século XX nos EUA, que vigorou até a década de 1970, o toyotismo e o just in time, introduzido pela Toyota, verifica-se que as características são carregadas de técnicas cientificas informacionais com um elevado investimento em inovações (ROCHA FILHO, 1998), além da mecanização do sistema de produção.

Neste cenário, os sistemas de transportes, responsáveis por operacionalizar a logística que movimenta bens materiais e imateriais, estão ocupando importantes lugares na agenda dos geógrafos, planejadores e do Poder Público. Isso se deve pela preocupação com os "espaços globalizados". Assim, a circulação aparece como uma necessidade extrema, considerando a produção e estrutura como fatores essenciais para sua manutenção e sucesso.

Diante das características apresentadas e da relevância do setor para o desenvolvimento econômico do país, é interessante discutir sobre a rede de transportes das indústrias automobilísticas. É possível perceber que a maioria dos custos logísticos se deve ao transporte para movimentação de matérias-primas e/ou produtos acabados em grande parte das empresas.

Para Nazário (2000), em média, 60\% das despesas logísticas da empresa, é representada pelo transporte. Dessa forma, é de extrema relevância a redução dos custos para maior faturamento e lucro, seja através do desenvolvimento de tecnologias que permitam a utilização de equipamentos, seja por ações como a intermodalidade ou a terceirização da atividade para prestadores de serviços a fim de tornar mais competitiva área.

A área de logística conta com três modais de transporte, que é o terrestre, dividido entre rodoviário, dutoviário e ferroviário; o aquaviário, também conhecido como hidroviário, 


\section{A logística e as indústrias automobilísticas no Brasil}

Kátia Kelly Lacerda de Freitas; Luiz Andrei Gonçalves Pereira; Pedro Ivo Jorge Gomes

lacustre ou marítimo; e o aéreo. A escolha em utilização de qualquer um dos modais dependerá de vários fatores, como o sistema utilizado, o volume dos bens, o tráfego, entre outros.

É importante salientar que há várias diferenças entre os modais que variam desde os custos fixos e variáveis, a frequência, a capacidade de carga, o desempenhos, ou seja, características diferenciadas considerando o nível de serviço a ser executado. Um dos maiores percalços encontrados pelo ramo logístico consiste na infraestrutura do transporte e nas falhas de comunicação, situação que foi minimizada com a globalização, permitindo mudanças tanto relacionada a avanços tecnológicos quanto pela alteração na produção de bens e serviços.

Uma discussão pertinente e atual que vem se desdobrando é sobre o termo rede, que tem como objetivo construir estudos e pesquisas que possam subsidiar as discussões relacionadas a distâncias e território na construção de técnicas (DIAS, 2005). Desse modo, a geografia contribui para a análise das redes existentes nos territórios, sejam as redes urbanas, de comércio ou de transporte, com a finalidade de traçar pontos desde o surgimento até os dias atuais, como forma de compreender as questões ligadas à produção, distribuição e circulação de matérias-primas, objetos e pessoas.

As redes e os sistemas de transportes via sistema produtivo capitalista, conhecem diversas transformações na qualidade dos fluxos, formando um conjunto de redes de informação. Nas palavras de Castillo e Trevisan:

Como a lógica de instalação ou adequação das infraestruturas territoriais de transporte é muito dependente das demandas na maioria das vezes ligadas ao trabalho da produção hegemônica, a integração territorial ocorre, principalmente nos países pobres, em função de interesses corporativos (CASTILLO E TREVISAN, 2007, p.26).

Com o passar dos anos, assistiu-se a uma evolução nas tecnologias de informação que contribuíram para os avanços nas cadeias logísticas. Houve grande crescimento em escala mundial, isso em consequência das atividades de logística e de transportes, como também, o gerenciamento da cadeia de suprimentos (supply chains), os procedimentos de compras e a distribuição (ROCHA FILHO, 1998).

A globalização fracionou e propagou as cadeias produtivas em grande escala, surgindo os blocos econômicos, induzindo a padrões inovadores de consumo e detenção da produção, favorecendo as cadeias produtivas, e, portanto, logísticas e os processos de distribuição de bens e serviços pelo mundo (BOTELHO, 2000). 


\section{A logística e as indústrias automobilísticas no Brasil}

Kátia Kelly Lacerda de Freitas; Luiz Andrei Gonçalves Pereira; Pedro Ivo Jorge Gomes

Neste período, houve uma ampliação e aprofundamento da divisão territorial do trabalho via sistemas de transportes, em que permitiram que os países fossem capazes de oferecer modais de transportes com menores custos, favorecendo a inserção no mercado internacional.

A partir da década de 1990, houve um fortalecimento dos sistemas de concessões rodoviárias e ferroviárias, o que permitiu que normas territoriais favorecessem as transformações vividas recentemente no país, principalmente ao verificar as concessões rodoviárias ocorridas que apontam para os altos custos advindos da exploração privada, entretanto, permitiram uma melhoria na qualidade dos serviços prestados.

Desta forma, pode-se inferir que a indústria automobilística possui muitas peculiaridades, o que faz com que tenha uma base de difícil comparação, em função da produção, comercialização e consumo que variam conforme são consideradas outras variáveis. Esse fato permite que cada etapa de produção de um automóvel seja realizada sem a existência prévia de uma peça ou um recurso.

Assim, a geografia desempenha um papel peculiar, visto que os lugares exercem uma função de inclusão nas redes pensando principalmente a partir da nova divisão do trabalho, das hierarquias e posições. Os lugares são reformulados, e através da inclusão das redes, são formadas novas divisões de trabalho, novas hierarquias e posições.

Na perspectiva de Santos,

É no território que a ação em rede (e das redes) praticada pelas grandes empresas ganha caráter local e efetivamente se mostra como elemento organizador e normatizador das ações e da vida nos lugares, pois neles ela se integra e se dissolve através do trabalho coletivo (SANTOS, 1994, p. 268).

A infraestrutura de redes exerce uma função singular nos sistemas de transporte, que ao serem integradas produzem efeitos satisfatórios. As redes podem ser classificadas como técnicas ou territoriais. Para Santos (1994), a circulação de mercadorias e pessoas é essencial para o trabalho, sendo o sistema de transporte responsável pelos diferentes fluxos de materiais.

As redes de transportes no século XXI se tornam indispensáveis para a compreensão e funcionamento do território, principalmente quando são redefinidas pelas potencialidades técnicas, precipuamente se considerado o oligopólio concentrado e diferenciado do setor automotivo, visto que é representado por grandes grupos empresariais segundo Latini (2007) e Possas (1985), que possui diversos produtos e um grande volume de capital. 


\section{A logística e as indústrias automobilísticas no Brasil}

Kátia Kelly Lacerda de Freitas; Luiz Andrei Gonçalves Pereira; Pedro Ivo Jorge Gomes

\section{Os mercados importadores das indústrias Automobilísticas no Brasil}

A indústria automobilística é movida pela produção de veículos automotores de diferentes tipos e que variam de tamanhos e tipos, bem como pela montagem e desmontagem e comercialização de peças, podendo uma mesma empresa atuar em diferentes linhas ao mesmo tempo. Segundo Costa e Henkin (2016):

As montadoras costumam possuir plantas especializadas por tipos de veículos e por suas plataformas, onde se produzem os modelos que as utilizem e seus derivativos. Quanto ao tamanho, as montadoras podem ser consideradas de grande porte, em relação à estrutura industrial da economia, devido ao padrão tecnológico do setor e à amplitude do mercado atendido. Devido à complexidade tecnológica no desenvolvimento de veículos e em seu processo de fabricação, o setor incorre em custos fixos de elevada magnitude: gastos em pesquisa e desenvolvimento ( $\mathrm{P} \& \mathrm{D})$, propaganda, custos de setup, investimentos em máquinas e equipamentos, montagem de infraestrutura produtiva, etc. Assim, as empresas buscam abater esses custos por intermédio da obtenção de economias de escala e de escopo. Além disto, as montadoras procuram elevar a margem de lucro pela diferenciação de produtos (COSTA; HENKIN, 2016, p. 461).

Percebe-se, diante disso, que o setor automobilístico industrial, para alcançar o patamar de grande peso na economia mundial, carece de investir e movimentar outros setores para obter um diferencial em seus produtos.

A indústria automobilística possui uma estreita relação com a economia, isso pelo grau de ligação que estabelece com outros setores e serviços. Logo, é notório que o número de pessoas que trabalham nesta indústria é bastante expressivo, mesmo considerando que a incidência da mecanização da produção e automação impactou o número de postos de trabalho. Segundo Dicken (2010), de nove a dez milhões de pessoas trabalham seja direta ou indiretamente no setor. A indústria do petróleo responsável por mais da metade do consumo mundial, sendo $50 \%$ de borracha, $25 \%$ de vidro e $15 \%$ de aço.

Assim, pode-se inferir que a indústria automobilística se resume em montadoras que possuem uma estrutura mais complexa e interligada a diversos fornecedores de componentes. Para a construção de um veículo e sua finalização as montadoras são responsáveis por três processos de fabricação, sendo o primeiro a estrutura do veículo, que é a carroceria, o segundo a fabricação dos componentes; e o terceiro, o motor e a transmissão. 


\section{A logística e as indústrias automobilísticas no Brasil}

Kátia Kelly Lacerda de Freitas; Luiz Andrei Gonçalves Pereira; Pedro Ivo Jorge Gomes

Conforme afirma Dicken (2010), é possível observar a desverticalização, dos processos de fabricação junto às montadoras, que é uma característica do toyotismo:

Os fornecedores de primeiro nível fornecem os principais sistemas de componentes diretamente para as montadoras, e tem muita experiência em pesquisa e desenvolvimento em design. Os fornecedores de segundo nível geralmente produzem para os designs fornecidos pelas montadoras ou pelos fornecedores de primeiro nível, enquanto os fornecedores de terceiro nível abastecem os componentes mais básicos (DICKEN, 2010, p. 303).

Para Dicken (2010), o desenvolvimento da indústria ocorre em quatro estágios: O primeiro é a importação de veículos completos, considerado pouco eficiente em função dos altos custos e aproveitamento logístico; o segundo estágio é a montagem em território nacional dos componentes, momento que é considerada as condições do país de destino a fim de otimizar os custos. O terceiro estágio é a etapa que parte do veículo é importado e a outra produzida no seu destino, e, por fim, o quarto estágio, é nível em que o veículo é totalmente produzido no local e dependerá das condições da indústria montadora no momento.

Assim, a redistribuição geográfica da produção mundial das indústrias automotivas, bem como as alterações no mapa de consumo, considerando os mercados estratégicos, ocorreu e se expandiram nos países emergentes, contribuindo para que o setor chegasse ao patamar de sétimo maior produtor no Brasil, e no mercado mundial, o quarto maior. O fluxo internacional do comercio passou por processo de reorganização da produção e dos consumos mundiais. A análise de rede, quando aplicada ao comércio, permite que as trocas bilaterais entre importadores e exportadores sejam observadas, e que as relações de troca possam se estabelecer entre os países.

Considerando os produtos automobilísticos nos dados sobre as importações, verificase que houve pouca mudança no período de 2000 a 2007, sendo os EUA um dos maiores importadores, seguido da Alemanha, Reino Unido e Canadá. A Rússia estava entre os 10 maiores importadores (ANFAVEA, 2010).

Neste contexto, pode-se afirmar que o processo de globalização contribuiu para a evolução desta indústria, com grande intensificação da introdução de novas tecnologias com estratégias competitivas que foram implementadas, favorecendo a conquista de novos mercados.

Um exemplo interessante é a Ford, que vivenciou intensamente esse processo, favorecendo uma otimização dos custos através de alterações nos modelos dos veículos, 


\section{A logística e as indústrias automobilísticas no Brasil}

Kátia Kelly Lacerda de Freitas; Luiz Andrei Gonçalves Pereira; Pedro Ivo Jorge Gomes

ampliando a escala de produção. Já a Toyota utilizou a globalização como forma de elevar seus lucros e expandir a capacidade produtiva, lançando mão da regionalização e desenvolvimento de novos modelos, com diversas versões.

A VW, considerada maior produtora europeia de veículos, alcançou o quinto lugar como maior fabricante mundial. No caso da Fiat, ficando com a sétima posição com a maior produtora de automóveis do mundo e a quarta da Europa, isso no ano de 1999. Contudo a empresa procurou grande diversificação das suas vendas geograficamente, com aumento expressivo nas linhas de veículos médios e atualização de novos modelos. Nos anos 2000 obteve junto a GM, uma aliança defensiva estratégica (BOTELHO, 2000; DICKEN, 2010).

\section{Considerações Finais}

O artigo apresentou um estudo da logística, bem como, uma discussão acerca indústrias automobilísticas a partir de uma revisão bibliográfica, em que foi possível verificar a importância das indústrias automobilísticas para o crescimento e desenvolvimento da economia do país.

Foi possível perceber que a realidade do setor automobilístico brasileiro, após o processo de globalização, quando as empresas instaladas foram obrigadas a adotar estratégias e ações como forma de aumentar seu desempenho e produtividade, contribuindo para a participação e competitividade no mercado internacional. A logística exerce um papel importante neste sentido, uma vez que permite tanto clientes quanto fornecedores e empresas atendam seus interesses de forma eficiente, contribuindo para agregação de valores de seu produto.

Dentre as atividades desempenhadas pela logística, há de se considerar o planejamento, a organização e administração desde a matéria-prima ao produto acabado, inclusive a entrega no consumidor final e no pós-venda, buscando atender, no menor tempo e custo possível, entretanto, a logística ainda conta com um gasto muito significativo, possuindo alto valor com o transporte que, conforme apontado, chega a ser responsável por $60 \%$ das despesas.

Assim, verificou-se uma conquista significativa das indústrias automobilísticas nos últimos anos através do auxílio e emprego de altas tecnologias, bem como, de técnicas de intermodalidade e terceirização de atividades, permitindo o alcance de lucro expressivo, mesmo em um mercado tão competitivo e oligopolizado. 


\section{A logística e as indústrias automobilísticas no Brasil}

Kátia Kelly Lacerda de Freitas; Luiz Andrei Gonçalves Pereira; Pedro Ivo Jorge Gomes

\section{Referências}

BALlOU, R. H. Gerenciamento da Cadeia de Suprimento: Logística Empresarial. 5 Edição, Ed. Artmed, 2004.

BALLOU, R. H. Logística e Empresarial: Transporte e Administração de Materiais, Distribuição Física. Ed. Atlas, 1993.

BORDENAVE, G. Globalization at the heart of organization change: crisis and recovery at the Ford Motor Company. In: FREYSSENET, M.; MAIR, A.; SHIMIZU, K.; VOLPATO, G. (eds). One Best Way? Trajectories and Industrial Models of the World's Automobiles Producers. London: Oxford University Press, 1998. p. 365- 394.

BOTELHO, A. Reestruturação produtiva e produção do espaço: o caso da indústria automobilística instalada no Brasil. Revista do Departamento de Geografia. São Paulo, 2002, n. 15 , p. 55.

BURSA, M.; HUNSTON, H.; LEWIS, A. WRIGHT, C. Transplant and Beyond: the internationalisation of the word's automotive manufacturers. London: Financial Times Automotive, 1998. p. 212.

CARVALHO, E. G. de. Globalização e estratégias competitivas na indústria automobilística: uma abordagem a partir das principais montadoras instaladas no Brasil. 2003. 274 f. Doutorado. (Doutorado em Economia) - Universidade de Campinas-UNICAMP, Campinas, 2003.

CASTILLO, R.; TREVISAN, L. Reacionalidade e controle dos fluxos materiais no território brasileiro: o sistema de monitoramento de veículos por satélite no transporte rodoviário de cargas. In: DIAS, L. C.; SILVEIRA, R.L.L. da. (Org.) Redes, Sociedade e Territórios. 2 ed. Santa Cruz do Sul: EDNISC, 2007.

DINIZ, C. C. Desenvolvimento poligonal no Brasil: nem desconcentração nem contínua polarização. Revista Nova Economia, v. 31, n. 11, p. 35-64, 1993.

DINIZ, C. C. (2000). Impactos territoriais da reestruturação produtiva. In: RIBEIRO, L. C. de Q. (org.) (2000). O futuro das metrópoles: desigualdades e governabilidade. Rio de Janeiro, Revan. FASE, p. 21-61.

DINIZ, C. C.; CROCCO, M. Reestruturação econômica e impacto regional: o novo mapa da indústria brasileira. Nova economia, v. 6, n. 1, p. 77-103, 1996.

DICKEN, Peter. Mudança Global - Mapeando as Novas Fronteiras da Economia Mundial. São Paulo, Brookman, 2010.

GUIMARÃES NETO, Leonardo. Introdução à formação econômica do Nordeste. Recife, Fundaj/Massangana, 1989.

LATINI, S. A. A Implantação da Indústria Automobilística no Brasil: da substituição de importações ativa à globalização passiva. São Paulo: Alaúde Editorial, 2007. 391p.

MAXTON, G. P. World car forecasts: the outlook for sales, production and vehicles in use to 2005. Research Report. London, 1998. 


\section{A logística e as indústrias automobilísticas no Brasil}

Kátia Kelly Lacerda de Freitas; Luiz Andrei Gonçalves Pereira; Pedro Ivo Jorge Gomes

MOURA A. R, Dicionário de Logística. São Paulo: IMAN, 2004.

NAZÁRIO, P. [et.al]. O Papel do Transporte na Logística. São Paulo: 2000.

POSSAS, Mário L. Estruturas de mercado em oligopólio. São Paulo: Hucitec, 1985.

ROCHA FILHO, M. F. da. Concorrência cresce com novas fábricas e quedas nas vendas. O Estado de S. Paulo, 29 nov. 1998.

SANTOS, Milton. Técnica, Espaço, Tempo. Globalização e meio técnico-científicoinformacional. São Paulo: Hucitec, 1994a.

STOREY, J. The world's car manufacturers: a strategic review of finance and operations. London: Financial Times Business Ltd, 1998.

WANDERLEY, L. Caracterização Industrial e Transformações da Década de 1990: Brasil e Nordeste. In: ROSA, A.; KHAN, A. (orgs.) Nordeste: Reflexões sobre aspectos setoriais e locais de uma economia. Fortaleza: CAEN, 2002. 